\title{
Publishing in Good Journals
}

\author{
Ian Sanders sandeid@unisa.ac.za (CorResponding)
}

${ }^{a}$ Department of Computer Science, School of Computing, University of South Africa, South Africa

\section{INTRODUCTION}

Academics have, for many years, been under the threat of "publish or perish" (Gad-el-Hak, 2004; Garfield, 1996). South African academics have also felt this pressure with their universities chasing the money paid out by the Department of Higher Education and Training (DHET) in terms of "research incentive funding". Conference proceedings publications and journal articles are both accepted by DHET although journal articles earn more units. In recent times, however, South African academics have come under increasing pressure to publish in journals on the DHET "lists". In some instances, academics receive increased incentives if they publish in "good journals". For many academics in the computing disciplines, moving from publishing in conferences to publishing in journals is a difficult transition.

As a section editor of the South African Computer Journal and as a reviewer elsewhere, I have come to realise that many emerging academics from South Africa and other parts of the world do not really appreciate what it takes to have an article published in a journal. In addition, they jeopardise their chances of being published by inadvertently plagiarising, or by insufficient attention to detail, in the preparation of their submissions.

The intention of this article is to provide some guidance, based on experience, for publishing in journals. Section 2 considers these ideas. Obviously almost all of these comments could apply equally to conference submissions but remember that good journals are typically more thorough in checking details and have more time to do so and thus you are more likely to be found out if you are careless.

\section{GUIDELINES}

\section{Read good research}

Reading voraciously is the starting point for any good research. Reading allows you to understand the state of the art and find the gaps to be filled (potentially by your research). If you do

Sanders, I. D. (2018). Publishing in Good Journals [Viewpoint]. South African Computer Journal 30(2), 73-79. https: //doi.org/10.18489/sacj.v30i2.652

Copyright (C) the author(s); published under a Creative Commons NonCommercial 4.0 License (CC BY-NC 4.0).

SACJ is a publication of the South African Institute of Computer Scientists and Information Technologists. ISSN 1015-7999 (print) ISSN 2313-7835 (online). 
not read, you cannot know what other people are doing and what is still to be done. Read articles published in the leading/prominent journals in your field.

Do not read passively! Think critically about what you are reading. For every article that you read, ask yourself questions like:

- Did I enjoy reading the article?

- Was the article well written?

- If the article was well written, what worked?

- If the article was badly written, what did not work? What was lacking? What was badly explained? What could have been improved?

- Did I learn something from reading the article? If so, what?

- Is the content of this article related to content in other articles I have read and, if so, how?

- Is the article relevant to my (proposed) research and, if so, how?

- Is this article "core" to my research endeavour?

Reading is also important for seeing how good research is written up and presented. Generally, articles published in journals have met a minimum standard as concerns style, grammar and layout. If you read a well written article, you will see how the author's effort makes the argument easier to follow and allows you to get more out of reading the paper. Some journals may publish articles that report good research but do so badly - for example, the writing is poor, the explanations are unclear, or the language is confusing. Such papers are hard to read and hard to make sense of. Use your knowledge of the weaknesses of other articles to produce better written articles.

\section{Do good research}

This should be obvious but sometimes appears not to be! You might get away with a limited study or a study that only makes a small contribution in a conference proceedings. This is unlikely to be the case in a good journal. You will need to make a significant contribution and have done a well planned and thorough study and really applied your mind to the analysis of the results and the critical discussion thereof. In addition, you should have written it up coherently.

Most journals have a list of questions that they send to reviewers. These often include questions like:

- Is the abstract a concise account of the work and conclusions?

- Is the literature review a satisfactory background to the work?

- Is the research methodology adequately described and justified?

- Are the results adequately presented and analysed? 
- Have alternative interpretations of the data been considered?

- Are the conclusions supported by the data?

- Are the conclusions discussed in the context of other research in the area?

- Is the arrangement of material satisfactory?

- Is the use of language acceptable?

- Are the figures and tables clear and well laid out?

- What is the contribution made by the article?

Think about the answers to these questions in terms of the article you plan to submit.

\section{Choose an appropriate journal for your research}

Take time to find an appropriate journal to which to submit your article. Most (decent) journals include a list of areas where they are prepared to consider articles. Read the information for authors to find out what articles a given journal is likely to publish. You can also use a Journal Selector Tool to assist you in finding an appropriate journal. If you are still unsure, email the journal editor and ask! If you send your article to a journal that does not accept articles in the field that your article is in, it will be rejected.

Note that for subsidy purposes authors based at South African universities should choose journals on one of the "lists" published by DHET. The research office at your institution should be able to supply you with a current copy of the lists.

\section{Decide whether the chosen journal is "good"}

There are many different metrics which can be used to determine whether a journal is "good". The Journal Impact Factor ${ }^{1}$ (JIF) is often used in the sciences. These metrics are controversial (Moustafa, 2015; Seglen, 1997) and should be used carefully but they can give you a guide as to the quality of a journal. As an additional check, see if any articles in the journal are reasonably highly cited (you can use Google Scholar to do this).

In some fields of research there are journal ranking lists. For example, the MIS Journal Rankings ${ }^{2}$ and Top Journals for Computer Science and Electronics ${ }^{3}$ sites provide such lists. These can also be used to determine the quality of a journal.

Avoid predatory and counterfeit journals. Predatory journals typically charge a high publication fee and publish articles which are essentially unreviewed and uneditted. Counterfeit journals typically mimic an existing journal and charge fees for reviewing an article which is often not actually published anywhere (Singh \& Remenyi, 2016).

\footnotetext{
${ }^{1}$ https://www.scijournal.org/

${ }^{2}$ http://www1.chapman.edu/ bdehning/MIS\%20Journal\%20Rankings.htm

${ }^{3}$ http://www.guide2research.com/journals/
} 
If you publish in a place that is poorly regarded, not only does that potentially damage your CV (or your Google Scholar profile) but if you waste good results on a journal you would be embarrassed to cite, you cannot refer to those results in future.

\section{5. "Sell" your research}

Be explicit about your contribution! Do not leave it for the reviewers to figure out what you added to the field. If you are embarrassed or apologetic about your contribution, you probably did not achieve point 2 above and so will not get published anyway.

\section{Write up your research properly}

You need to very carefully plan your article. Start at a high level. Decide what you are going to present and in what order you are going to present it. Then do the same for each section of the article. Then make sure that you have a consistent, coherent flow.

Make sure that technical issues such as grammar, spelling and layout are correct. If you are not a good writer, get someone else to read and correct the article.

\section{Follow the publication instructions given by the journal}

If the journal has a prescribed layout/format, make sure that your article conforms. Most journals give you clear instructions. If they do not, you should probably not send your article to them. Predatory journals typically accept articles in any layout.

Some journals will give you Word and/or $\mathrm{HT}_{\mathrm{E}} \mathrm{X}$ templates to use/copy for formatting the article and doing references. Use these to make sure that your article is formatted correctly.

If your article does not comform to what the reviewers expect, it comes across as sloppiness or arrogance and your article is more likely to be rejected.

\section{Make sure that you cite the seminal articles in the field}

All areas have some key articles and some key "names"! Make sure that you do not "miss" these. If this is your research area, you should know these articles and the names.

\section{Cite recent articles}

If you do not cite the most recent work in your area, it is clear to the reviewers that you have not done a thorough literature review. Do a thorough search of the relevant databases when you start your research and then use alerts to make sure you do not miss any new articles.

If there are no recent articles in your area - which could happen - then you need to cite peripherally related/similar articles to argue why they are not what you are doing!

10. Cite key articles to show the progession of the research in the field

Typically any field of research develops over the years as new work is published based on the earlier work. Make sure that you trace the important articles from the seminal articles to the 
most recent work. Also, make sure that you trace the important ideas/concepts from the early articles even if these are not cited in the newer articles.

The articles that you cite should be those which most closely relate to your own research. Do not cite articles which do not really relate to your work. This could be seen as "reference padding" and will detract from, rather than enhance, your work.

\section{Cite related articles from the journal in which you are trying to publish}

If you have chosen the journal wisely then there are likely to be other articles in the same area that have been reviewed and accepted by the reviewers of that journal. The reviewers are likely to read the journal for which they review and so are likely to know what has been published in the journal. If you do not cite these articles, you come across as not being thorough.

12. Cite related articles written by editorial board members of the journal in which you are trying to publish

Your reviewers are likely to be "names" in the area of your article, so they are likely to have published in the area. If you "miss" their articles, you are (again) seemingly sloppy. Reviewers have egos too!

Most journals have a list of reviewers (or a list of their editorial board members) somewhere that you can access it. Take some time to find the reviewers/board members in the area of your article and cite their articles if the articles are related/relevant. Sometimes it is even worthwhile arguing why those articles are not really "related".

\section{Do not "pad" your reference list}

In the points above I stressed citing "relevant articles" - do not cite articles that do not make a real contribution in the area of your research just to increase the length of your reference list.

In addition, note that a source contributing to your understanding of a concept in the area does not necessarily warrant that source being cited. Wikipedia, for example, is a good start for your initial reading but a poor reference to cite because it could change any time. Equally, you may read sections of a textbook to come to grips with some idea in your field but you should only cite the source that introduced that idea into the field.

\section{Plagiarism}

Plagiarism $^{4}$ is a problem for academics and academic publishers (Hong, 2017; Masic, 2012). Most journals will have some process of comparing the content of your article to work already published. If it seems that you have plagiarised material, or even inadequately paraphrased material, your article will most likely be rejected. Make sure that you run your article through a "similarity checker" and address any issues that the selected tool identifies before you submit it to a journal.

\footnotetext{
${ }^{4}$ https://www.plagiarism.org/article/what-is-plagiarism

${ }^{5}$ https://www.turnitin.com/ or http://www.ithenticate.com/
} 
An even worse consequence than your article being rejected is that your academic integrity is brought into question. Some journals will keep a list of authors they suspect of plagiarism. Other journals may report plagiarism to the author's institution.

\section{Authorship}

Talk to anyone who was involved in your work before you decide on authorship of the article and, where necessary, discuss whose names are listed and in what order. You do not want anyone to raise questions about the authorship after the article is accepted.

In addition, anyone you list as an author must be happy with the version of the article that you submit. So make sure all the authors have a chance to read, and comment on, the final version.

\section{Affiliation}

The affiliation (university, department) on your article should be where you did the work. This is particularly important in South Africa where the research incentive funding goes to the institution that is listed as the author's affiliation. If you have moved since doing the research, most journals will allow a footnote giving your current affiliation.

\section{Resources}

Your institutional librarians are a very valuable resource - they can assist you with literature searches, setting up alerts, using journal selectors and doing citation searches among other ways of supporting your research. Make use of them - it can make a big difference to the quality of your research.

Your more experienced colleagues are also a valuable resource. Talk to them. Do not learn from hard experience what they already know and (normally) are happy to share!

\section{CONCLUSION}

Doing research requires lots of thought, time and effort and getting one's research published in a good journal is the aim of all academics. Hopefully, the guidelines in this article will make getting published a little bit easier for emerging academics.

\section{ACKNOWLEDGEMENTS}

My name appears as the author of the article but, in fact, the article would not have been possible without the very valuable inputs from many colleagues - Philip Machanick, Trish Alexander, Isabel Venter, Filistea Naude, Shawren Singh, Colin Pilkington, Laurette Pretorius, Etienne van der Poel, Kirstin Krauss, to name a few.

I am sure that I "picked the brains" of other colleagues as well. If you did help me with this but your name is not on the list above, then please accept my apologies. 


\section{References}

Gad-el-Hak, M. (2004). Publish or perish - an ailing enterprise? Physics Today, 57(3), 61-62.

Garfield, E. (1996). What is the primordial reference for the phrase 'Publish Or Perish'? The Scientist, $10(12), 11$.

Hong, S.-T. (2017). Plagiarism continues to affect scholarly journals. Journal of Korean Medical Science, 32(2), 183-185. http://dx.doi.org/10.3346/jkms.2017.32.2.183

Masic, I. (2012). Plagiarism in scientific publishing. Acta Informatica Medica, 20(4), 208-213. http: //dx.doi.org/10.5455/aim.2012.20.208-213

Moustafa, K. (2015). The disaster of the impact factor. Science and Engineering Ethics, 21, 139-142. http://dx.doi.org/10.1007/s11948-014-9517-0

Seglen, P. O. (1997). Citations and journal impact factors: Questionable indicators of research quality. Allergy, 52(11), 1050-1056. http://dx.doi.org/10.1111/j.1398-9995.1997.tb00175.x. eprint: https://onlinelibrary.wiley.com/doi/pdf/10.1111/j.1398-9995.1997.tb00175.x

Singh, S. \& Remenyi, D. (2016). Researchers beware of predatory and counterfeit journals: Are academics gullible? The Electronic Journal of Business Research Methods, 14(1), 50-59. Retrieved from www.ejbrm.com/issue/download.html?idArticle $=435$ 